$a l .{ }^{1}$ and it gave a red coloration on heating with ninhydrin. In acid solution, its absorption spectrum displayed maxima at 235 and $265 \mathrm{~m} \mu$, the peaks corresponding presumably to the absorption due to the peptide and nucleotide moieties, respectively. The molecule was broken down into its constituent parts by treatment with cold alkalis, for example, sodium hydroxide, aqueous ammonia or hydroxylamine, the nucleotide portion displaying the chromatographic ${ }^{7}$, electrophoretic and light absorption properties characteristic of uridine- $5^{\prime}$-phosphate. The peptide-hydroxamic acid formed by treatment of the original nucleotide peptide with hydroxylamine behaved chromatographically as a single substance which on hydrolysis with acid yielded only arginine and $\alpha$-alanine as judged by chromatography and colour reactions ${ }^{8}$. The treatment with alkalis naturally resulted in the loss of reactivity towards hydroxylamine:

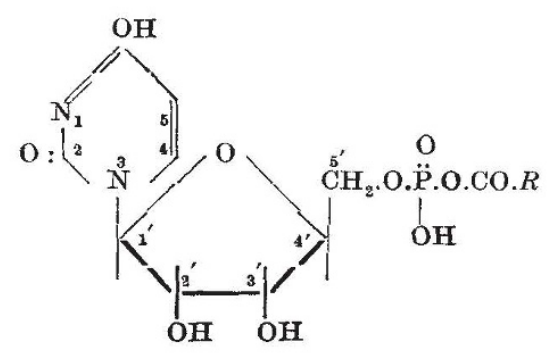

(II)

where $R$ represents a tetrapeptide residue consisting of two arginine and two $\alpha$-alanine units.

The presence of a uridylic acid residue in the nucleotide-peptide compound was confirmed by hydrolysing the latter material $(a)$ with formic acid to produce uracil, itself estimated by ion-exchange ehromatography ${ }^{9}$ (b) phosphate ${ }^{10}$ (1 mole), and (c) ribose (l mole $)^{11,12}$. The composition of the peptide was ascertained by hydrolysis with hydrochloric acid followed by chromatography on paper. The arginine and $\alpha$-alanine were eluted by means of dilute acid and estimated by the colorimetric method of Yemm and Cocking ${ }^{13}$, whereupon it was found that the molecule contained two residues each of the above amino-acids. The evidence indicates that the nucleotide-peptide now described is a mixed anhydride (II) of uridine-5'-phosphate with a tetrapeptide containing two units of $\alpha$-alanine and two units of arginine. The site of the 'active' anhydride grouping at the $5^{\prime}$-position of the uridine- $5^{\prime}$-phosphate is indicated $(a)$ by the loss of reactivity towards hydroxylamine coincident with fission of the molecule by means of alkalis, (b) the formation of a peptide-hydroxamic acid, and $(c)$ by the fact that the compound itself is immediately attacked by periodate, thus demonstrating the lack of substituents on the $2^{\prime}$ and $3^{\prime}$ positions. The close structural relationship between the nucleotidepeptide here described and the mixed 5 -phosphoanhydrides of adenosine- 5 '-phosphate with various single amino-acids, taken together with the fact that the latter anhydrides are held to be implicated in protein synthesis, suggests that the peptide derivatives also might play a part in cell growth.

${ }^{1}$ Koningsberger, V. V., van der Grinten, C. O., and Overbeek, J. T. G., Biochim. Biophys. Acta, 26, 483 (1957).

${ }_{2}$ Hrarris, G., Davies, J. W., and Parsons, R., Nature, 182, 1565 (1958).

${ }^{3}$ Berg, P., Fed. Proc., 16, 151 (1957) ; J. Biol. Chem., 233, 608 (1958).

${ }^{4}$ Kingdon, H. S., Webster, L. T., and Davie, E. W., Proc. U.S. Nat. Acad. Sci., 44, 757 (1958).

s MeCorquodale, D. J., and Mueller, G. C., Arch. Biochem. Biophys., 77, 13 (1958).

'Lambert, R., Zilliken, F., and Gurin, S., Angew. Chem., 70, 571 (1958).

${ }^{7}$ Kirby, K. S., Biochim. Biophys. Acta, 18, 575 (1955).

sepson, J. B., and Smith, I., Nature, 172, 1100 (1953).

${ }^{2}$ Cohn, W. E., Science, 109, 377 (1949).

${ }^{10}$ Umbreit, W. W., Burris, R. H., and Stauffer, J. F., "Manometric Techniques and Tissue Metabolism", 190 (Burgess, Minneapolis, 1951).

11 Mejbaum, W., Z. physiol, Chem., 258, 117 (1939)

${ }_{12}$ Fiske, C. H., and Subbarow, Y., J. Biol. Chem., 68, 375 (1925).

13 Yemm, E. W., and Cocking, E. C., Analyst, 80, 209 (1955).

\title{
SYNTHESIS AND PROPERTIES OF I-GLYCERYL-2-MYO-INOSITYL PHOSPHATE
}

$\mathrm{T}$ HE simplest member of the glycerinosityl phosphatides $^{1}$ is considered to be a diacyl derivative of 1-glyceryl-2-myo-inosityl phosphate $(\mathrm{I})^{2-4}$, since on hydrolysis it yields glycerol, myoinositol, glyceryl phosphate, myo-inosityl phosphate and fatty acids, the ratio fatty acids, glycerol, inositol, phosphorus being $2: 1: 1: 1$.

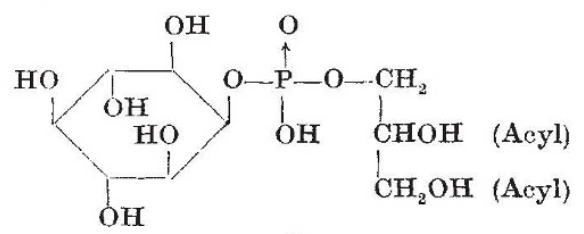

(I)

Although there is strong evidence for formula (I), doubt still exists concerning the position of the phosphate group because of its tendency to migrate to adjacent hydroxyl sites under the conditions of hydrolysis ${ }^{5,6}$. We have therefore synthesized 1-glyceryl-2-myo-inosityl phosphate for comparison with the natural product. This was kindly undertaken by Dr. J. N. Hawthorne, who found our syn. thetic product identical with his own specimen, isolated from ox liver and with a specimen synthesized by a different route (spo second cornmunication).

T. MALKIN

\section{Synthesis of I-Glyceryl-2-myo-inosityl Phosphate}

$3: 4: 5: 6$-TeTRACETYL-myo-INOSITOL ${ }^{7}$ in pyridine, when treated with 1.25 moles of acetyl chloride in benzene, yielded $1: 3: 4: 5: 6$-pentacetyl-myo-inositol in 78 per cent yield, shown by mixed m.p. $172-74^{\circ} \mathrm{C}$., and mixed m.p. of $p$-nitrobenzoyl esters $232-35^{\circ} \mathrm{C}$., to be identical with the pentacetate obtained by the stereospecific reduction of pentacetyl-scyllo-inosose ${ }^{8-10}$. This pentacetate, when treated with phenylphosphorodichloride, $1 \cdot 1$ moles, in lutidine at $40^{\circ} \mathrm{C}$. for $48 \mathrm{hr}$., followed by addition of $1: 2$-isopropylidene- 